\title{
Computational Investigation of the Causes of Wind Turbine Blade Damage at Japan's Wind Farm in Complex Terrain
}

\author{
Takanori Uchida \\ Research Institute for Applied Mechanics, Kyushu University, Fukuoka, Japan \\ Email: takanori@riam.kyushu-u.ac.jp
}

How to cite this paper: Uchida, T. (2018) Computational Investigation of the Causes of Wind Turbine Blade Damage at Japan's Wind Farm in Complex Terrain. Journal of Flow Control, Measurement \& Visualization, 6, 152-167.

https://doi.org/10.4236/jfcmv.2018.63013

Received: September 27, 2017

Accepted: July 1, 2018

Published: July 4, 2018

Copyright $\odot 2018$ by author and Scientific Research Publishing Inc. This work is licensed under the Creative Commons Attribution International License (CC BY 4.0).

http://creativecommons.org/licenses/by/4.0/

\begin{abstract}
During the passage of Typhoon 0918 (Melor) over southern Honshu in Japan on 7 and 8 October 2009, strong winds with extremely high turbulence fluctuations were observed over Shirataki Mountain and the surrounding mountains in Shimonoseki, Yamaguchi Prefecture, Japan. These strong winds caused damage to wind turbine blades at the Shiratakiyama Wind Farm owned by Kinden Corporation. In order to investigate the causes of the blade damage, the airflow characteristics from the time of the incidences are first simulated in detail with the combined use of the WRF-ARW mesoscale meteorological model and the RIAM-COMPACT LES turbulence model (CFD model). Subsequently, in order to evaluate the wind pressure acting on the wind turbine blades, an airflow analysis is separately performed for the vicinity of the blades with the RANS turbulence model. Finally, the stress on the blades is investigated using the FEM with the RANS analysis results as the boundary conditions.
\end{abstract}

\section{Keywords}

Wind Turbine Blade Damage, Complex Terrain, Meteorological Model, CFD Model

\section{Introduction}

During the passage of Typhoon 0918 (Melor) over southern Honshu in Japan on 7 and 8 October 2009, strong winds with extremely high turbulence fluctuations were observed over Shirataki Mountain and the surrounding mountains in Shimonoseki, Yamaguchi Prefecture, Japan. These strong winds caused damage to wind turbine blades at the Shiratakiyama Wind Farm owned by Kinden Corporation (see Figure 1 and Figure 2). In order to investigate the causes of the blade 


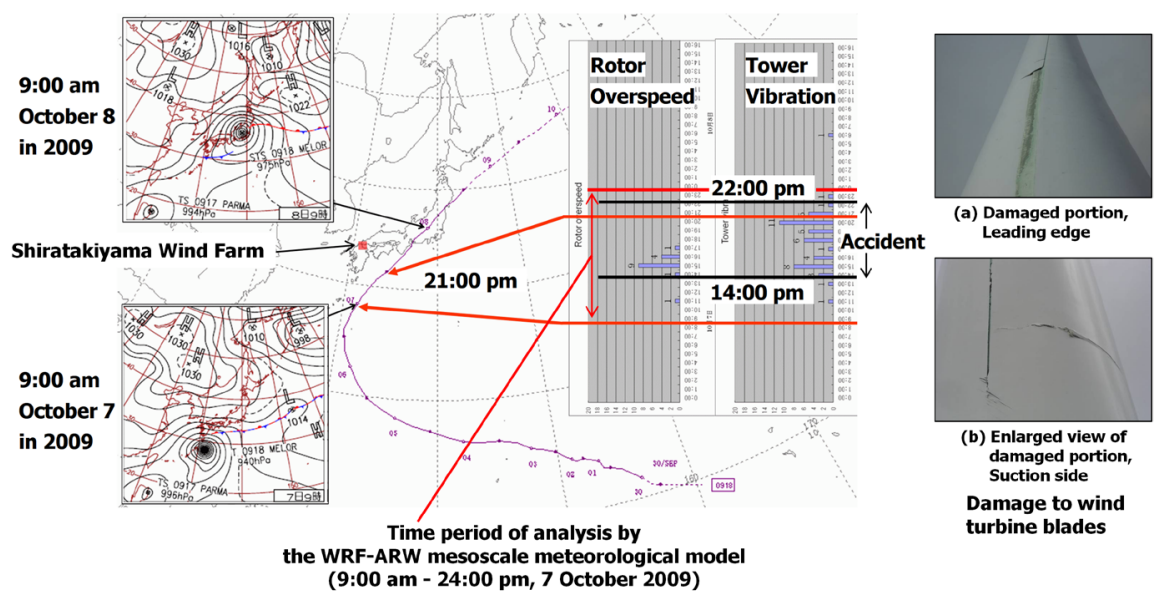

Figure 1. Track of Typhoon 18, 2009 (Melor). Time history of the number of turbine failures.

damage, the airflow characteristics from the time of the incidences are first simulated in detail with the combined use of the WRF-ARW mesoscale meteorological model [1] and the RIAM-COMPACT [2]-[10], which is based on a Large-Eddy Simulation (LES) turbulence model [11]. Subsequently, in order to evaluate the wind pressure acting on the wind turbine blades, an airflow analysis is separately performed for the vicinity of the blades with the RANS (Reynolds Averaged Navier-Stokes equation) turbulence model [12]. For this analysis, the time-averaged flow field acquired from the LES simulation is used for the boundary conditions. Finally, the stress on the blades is investigated using the Finite Element Method (FEM) with the RANS analysis results as the boundary conditions. Figure 3 summarizes the procedure of analysis for the present study.

\section{Simulation of Airflow Field with a Mesoscale Meteorological Model}

The regional-scale airflow field for the region including the wind farm is simulated using the WRF-ARW mesoscale meteorological model [1] which was developed primarily by the National Center for Atmospheric Research (NCAR), U.S.A. (https://www.mmm.ucar.edu/wrf-model-general). As illustrated in Figure 4, four levels of nesting are adopted within the computational domain. The height, vertical spatial resolution, and number of vertical grid points are all the same in the four nested analysis domains. The heights of the domains are 14.5 $\mathrm{km}$, and the domains consist of twenty-eight vertical grid layers with non-uniform grid spacing. As for the horizontal spatial resolution, the grid spacing for the innermost domain (Domain 4, Figure 4(d)) is $100 \mathrm{~m}$ and that for the outermost domain (Domain 1, Figure 4(a)) is set in such a way that the regional scale airflow field including the airflow field for a typhoon can be simulated. For the terrain elevation data, the ASTER GDEM

(https://asterweb.jpl.nasa.gov/gdem.asp) which was developed by the Japan Aerospace Exploration Agency (JAXA) is used. Mesoscale objective analysis data 


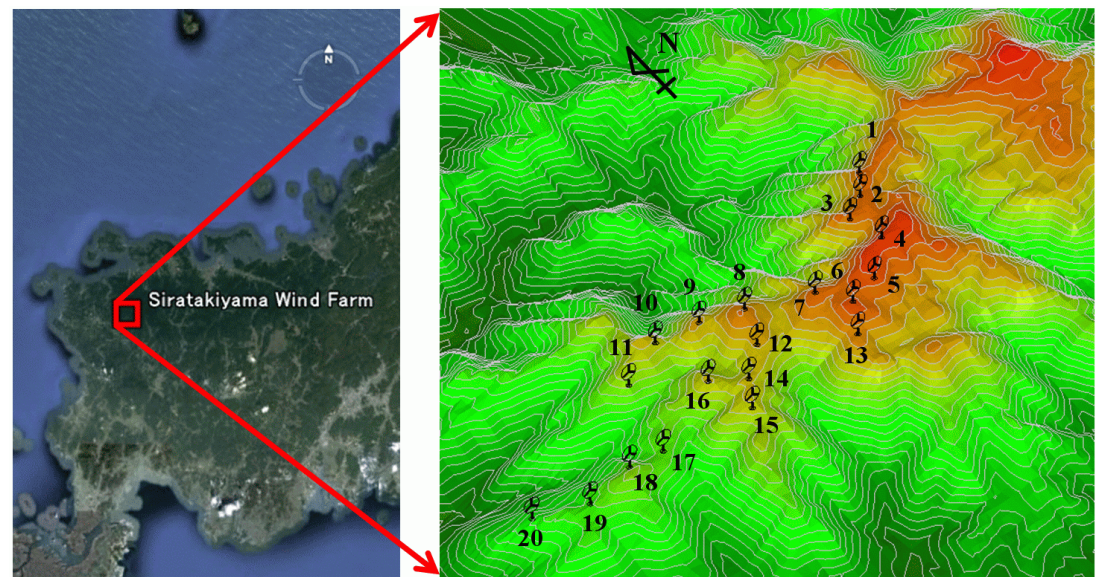

(a)

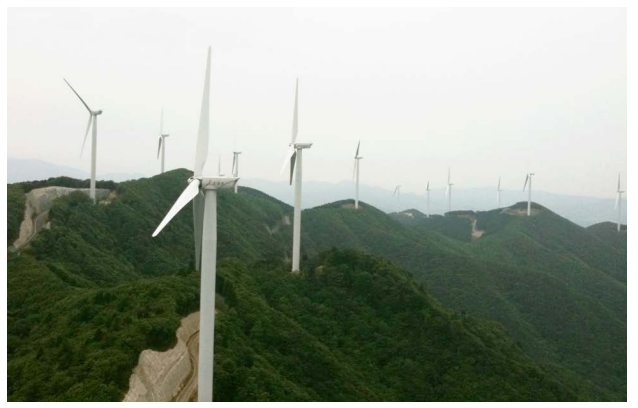

(b)

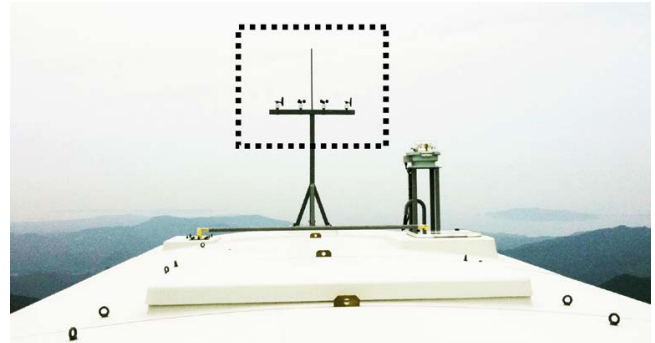

(c)

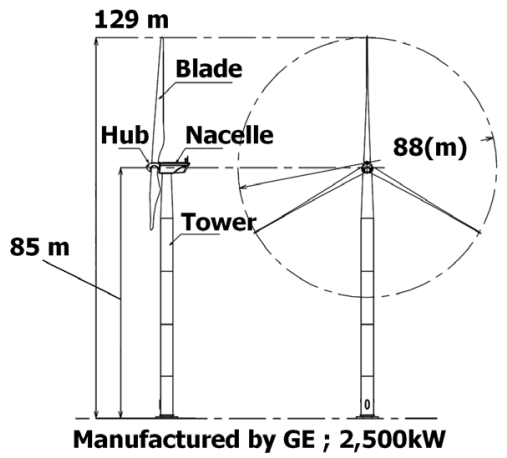

(d)

Figure 2. Location of the Shiratakiyama Wind Farm and wind turbine specifications. (a) Location of the Shiratakiyama Wind Farm in Japan; (b) Photo from No.1; (c) Wind vanes and 3-cup anemometers mounted on a nacelle (dotted line); (d) Wind turbine specifications. 


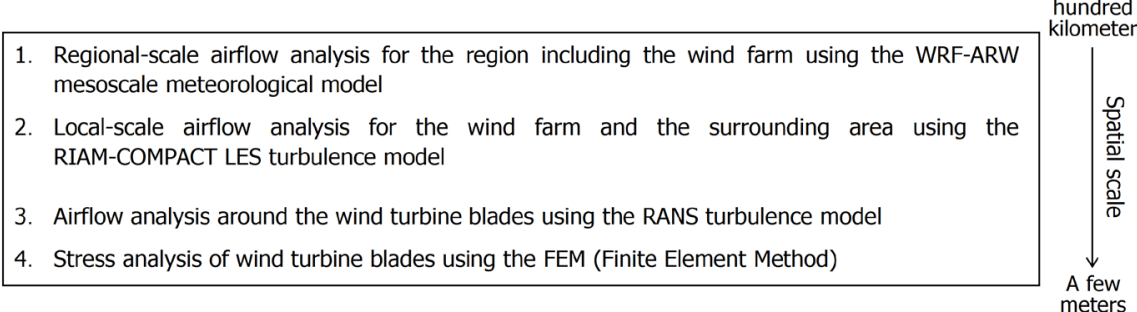

Figure 3. Procedure of analysis for the present study.

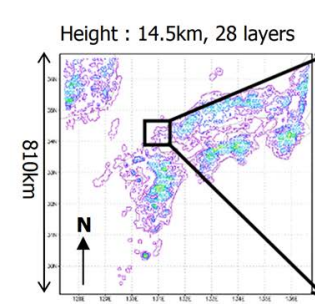

(a)

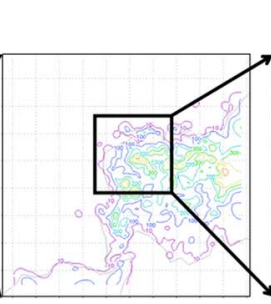

(b)

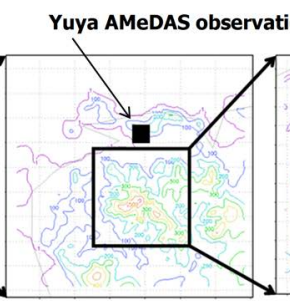

(c)

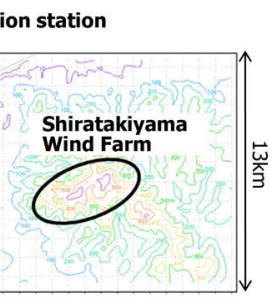

(d)

Figure 4. Analysis domains used for simulating the meteorological field with the WRF-ARW mesoscale meteorological model and four levels of nesting. (a) Domain 1 $(301 \times 301$ grid points, horizontal grid spacing: $2700 \mathrm{~m})$; (b) Domain $2(100 \times 100$ grid points, horizontal grid spacing: $900 \mathrm{~m})$; (c) Domain $3(100 \times 100$ grid points, horizontal grid spacing: $300 \mathrm{~m})$; (d) Domain $4(130 \times 130$ grid points, horizontal grid spacing: 100 $\mathrm{m})$.

from the Japan Meteorological Agency (JMA) are interpolated for eight times a day and used as boundary conditions for the outermost domain (Domain 1, Figure 4(a)). The simulation is started for 9:00 am on 7 October 2009, and time integration is performed up to $24: 00 \mathrm{pm}$ on the same day. Transfer of various information across the analysis domains is conducted using one-way nesting in which information is passed only from larger domains to smaller domains.

On 7 October 2009, the wind speed in the wind farm area started increasing in the afternoon. At the Yuya AMeDAS observation station (Figure 4(c)), the AMeDAS observation station closest to the wind farm, the maximum wind speed occurred at approximately 21:00 pm (Figure 5). At this time, the simulated value of the wind speed is between the AMeDAS time-averaged and maximum values of wind speed. On the other hand, the time series of wind direction is in close agreement between the simulated and observed data. The incidences of wind turbine blade damage started in the afternoon of 7 October. Examinations of the wind speed distribution in Domain 3 of the WRF-ARW mesoscale meteorological model in Figure 6(a) reveal that north-easterly wind was present near the ground surface and the wind speed increased with height around 14:00 $\mathrm{pm}$. However, the wind speed reached the maximum value at a height indicated by Arrow A and became close to zero around an altitude of $3 \mathrm{~km}$ (Figure 6(a)). Though not shown in the figure, the wind direction became westerly at altitudes above $3 \mathrm{~km}$ and the wind speed increased with height at these altitudes. In contrast, the wind direction near the ground around 22:00 pm (Figure 6(b)) became 
Observed value

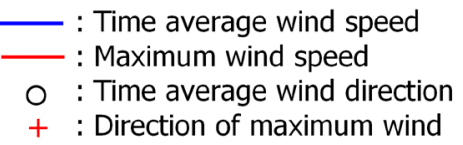

Simulated value

: Wind speed from Domain 2

: Wind speed from Domain 3

: Time average wind direction from Domain 2

: Time average wind direction from Domain 3

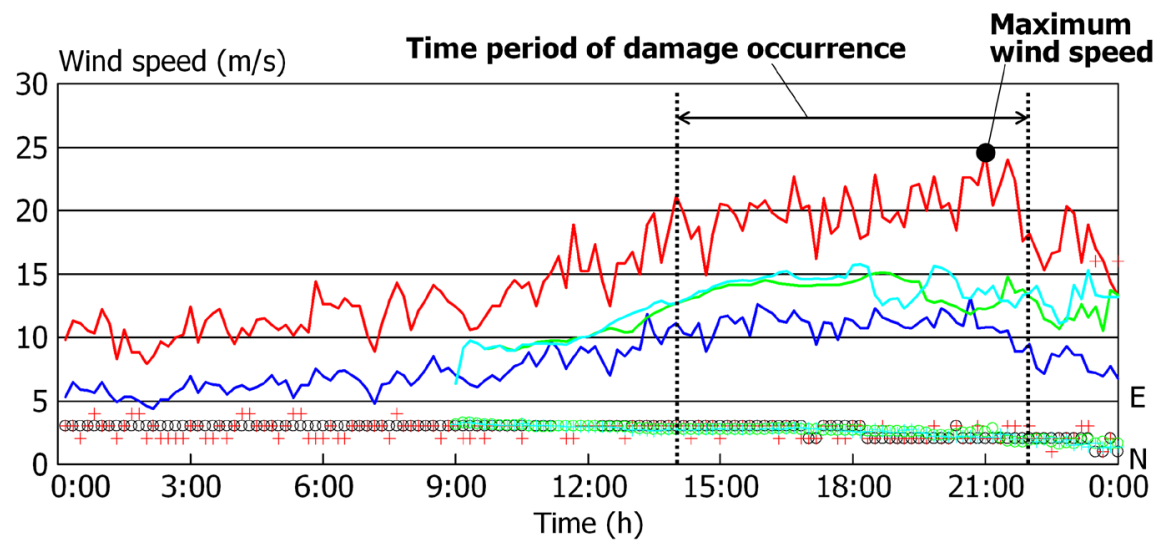

Figure 5. Temporal change of wind speed and direction at the Yuya AMeDAS observation station on 7 October 2009. Comparison between observed and simulated (WRF-ARW) values. Values are averages or maxima from 10-minute intervals.
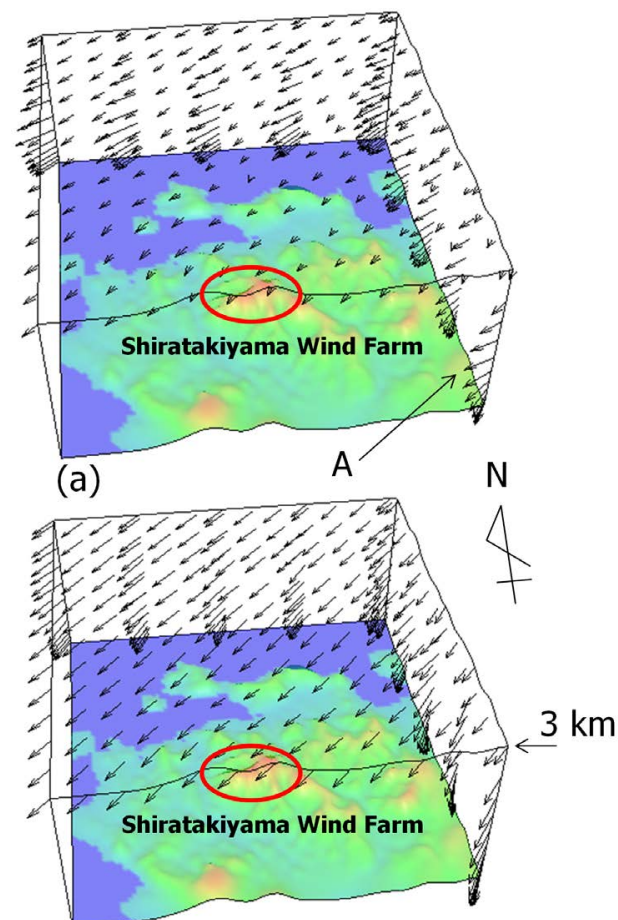

(b)

Figure 6. Wind velocity distributions in the afternoon of 7 October 2009, simulated values (WRF-ARW, Domain 3). (a) 14:00 pm; (b) 22:00 pm.

more northerly compared to that around 14:00 pm. Furthermore, around 22:00 $\mathrm{pm}$, north-easterly wind was present at an altitude of $3 \mathrm{~km}$, and the magnitude of the wind speed at this altitude was larger than that around 14:00 pm in Figure 6(a). 
An examination of the data from the cup and vane anemometer deployed on one of the wind turbine nacelles (see Figure 2(c), approximately $85 \mathrm{~m}$ above the ground surface) (solid line in Figure 7) suggests that the fluctuations of both wind speed and direction were large in the period after 19:00 pm in which the wind direction became northerly rather than north-easterly. These fluctuations occurred at the same time as the passage of a meteorological disturbance which was accompanied by rainfall. The fluctuations of the wind speed and direction simulated for the time period under consideration (dashed line in Figure 7) agree closely with those from the observations. Regarding the slight disagreement between the simulated and observed values of the wind speed and direction, the simulated values of wind speed are larger than the observed values. Furthermore, the frequency of the simulated wind speed fluctuations is lower than that of the observed wind speed fluctuations, thus the simulation was unable to reproduce the observed high-frequency fluctuations. Accordingly, an additional analysis is performed with an LES turbulence model which can more accurately simulate the temporal changes in the airflow than the WRF-ARW mesoscale meteorological model. For this simulation, the topographical relief surrounding the wind turbine generators is constructed in detail using high-resolution computational grids.

\section{Simulation of Airflow Field with an LES Turbulence Model}

Figure 8 shows the analysis domain of the LES turbulence model (RIAM-COMPACT [2]-[10]). This rectangular domain, which includes the wind farm, is set within Analysis Domain 3 of the WRF-ARW mesoscale meteorological model in such a way that the main axis (x-axis) is aligned with the northeast-southwest direction. As illustrated in Figure 9, the dimensions of the rectangular domain are $21 \mathrm{~km}, 10 \mathrm{~km}$, and $3.4 \mathrm{~km}$ in the $\mathrm{x}, \mathrm{y}$, and $\mathrm{z}$ directions, respectively. The numbers of grid points are 421, 201 and 51 in the $x, y$, and $z$

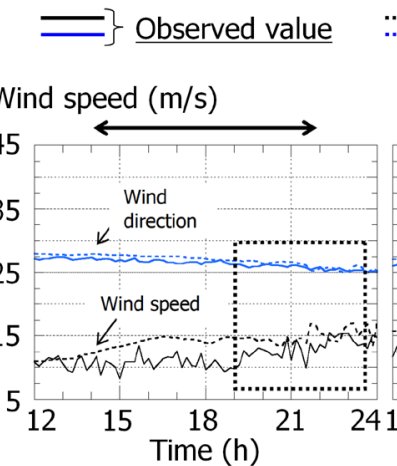

(a)

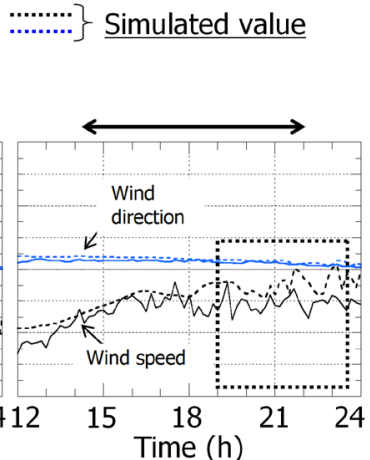

(b)

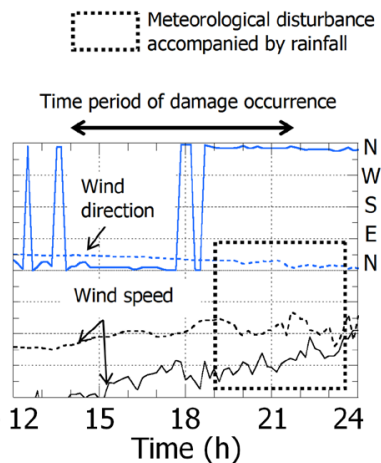

(c)

Figure 7. Comparison between the observed (10-minute average values) and simulated (WRF-ARW, Domain 3) values of the wind speed and direction at the height of the wind turbine nacelle for 7 October 2009. The observed values are from approximately $85 \mathrm{~m}$ above the ground surface. The simulated results are from a height of approximately $87 \mathrm{~m}$ above the ground surface. (a) Wind Turbine \#1; (b) Wind Turbine \#7; (c) Wind Turbine \#17 (see Figure 2(a)). 


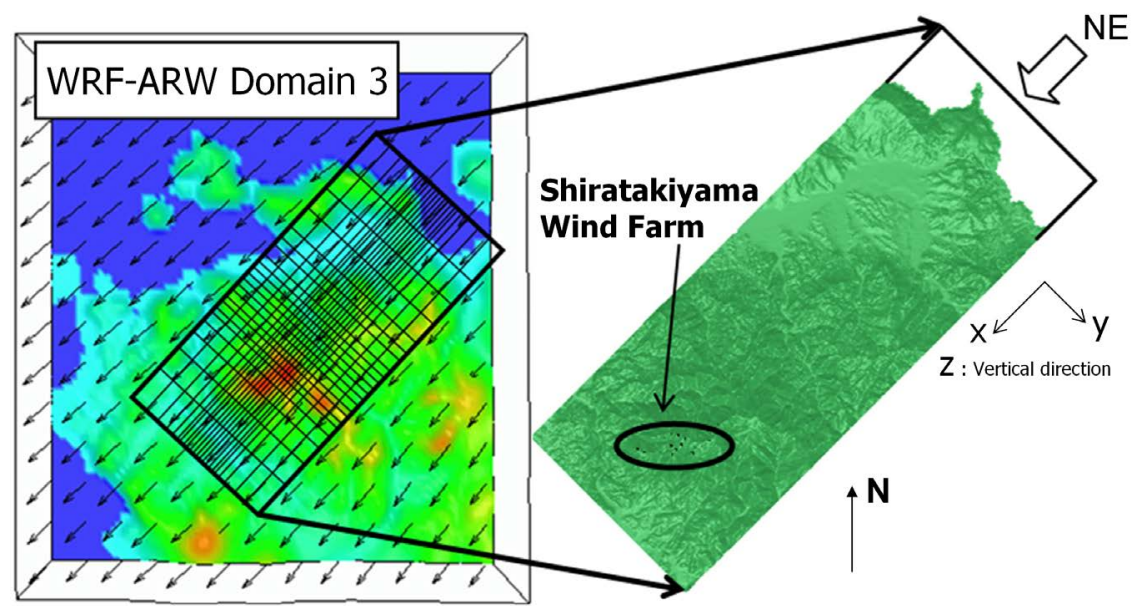

(a)

(b)

Figure 8. Analysis domain and terrain used in LES model (RIAM-COMPACT). (a) Analysis domain (wind velocity vectors are displayed by thinning the original data); (b) Terrain.

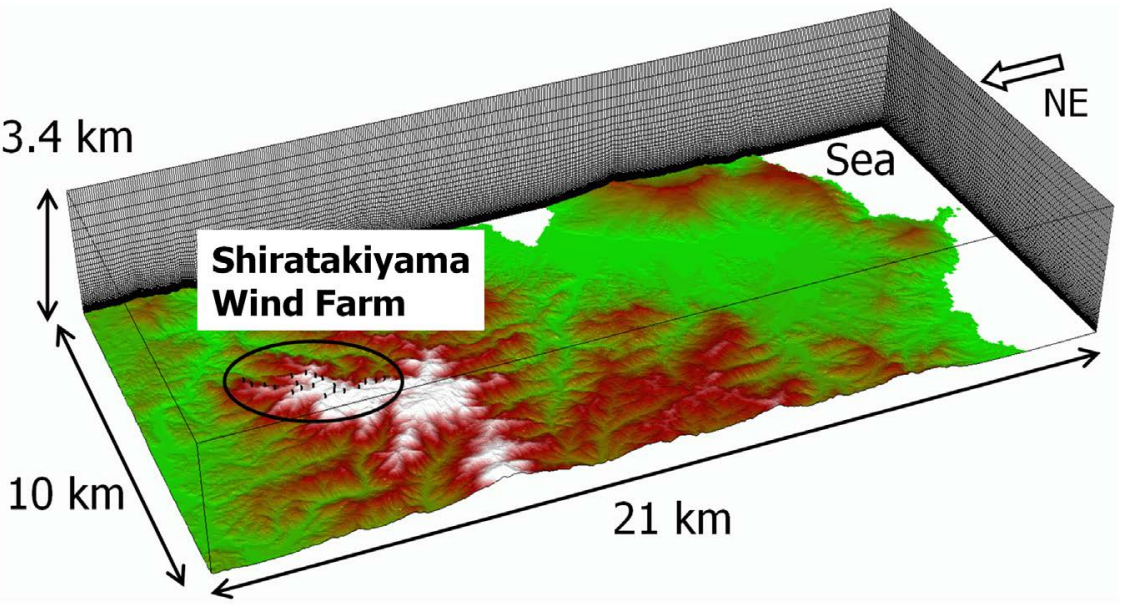

Figure 9. Computational grid used in the LES model (RIAM-COMPACT), 421(x) $\times$ $201(\mathrm{y}) \times 51(\mathrm{z})$ grid points.

directions, respectively. As for the spatial resolution, the grid points are spaced at an even interval of $\Delta x=\Delta y=50 \mathrm{~m}$ in the $\mathrm{x}-\mathrm{y}$ cross section; the grid points are spaced at uneven intervals of $\Delta \mathrm{z}=2 \mathrm{~m}$ to about $400 \mathrm{~m}$ in the $\mathrm{z}$-direction so that the grid cells are distributed with higher density in the vicinity of the ground surface.

Regarding the simulation with the LES model (RIAM-COMPACT), the simulation results from Domain 3 of the WRF-ARW mesoscale meteorological model (Figure 10) are interpolated and provided as inflow boundary conditions. The temporal change in the wind speed and direction simulated by the WRF-ARW mesoscale meteorological model for the height of $681 \mathrm{~m}$ above the ground surface at the inflow boundary of the LES model (RIAM-COMPACT) is shown in Figure 11. This height corresponds to the maximum altitude in the analysis 


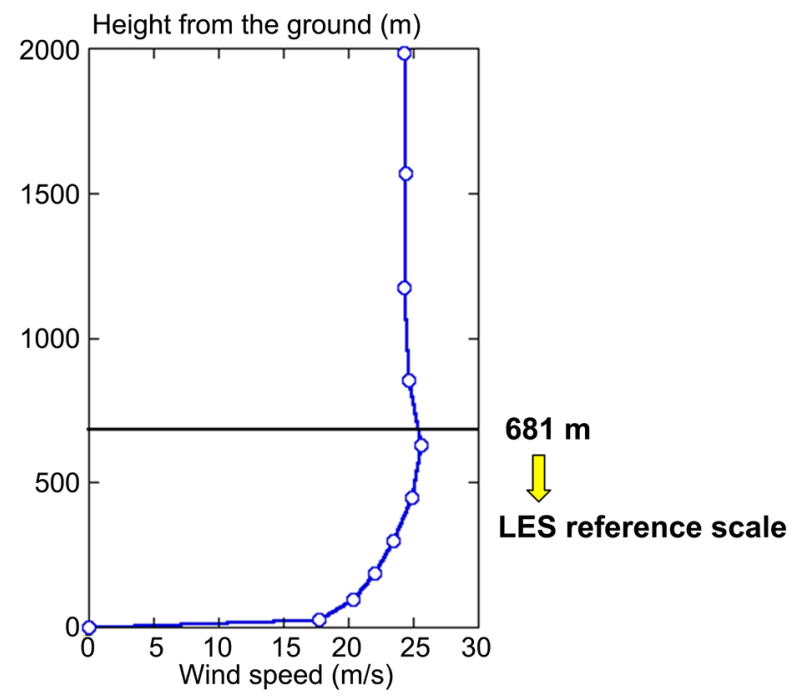

Figure 10. Vertical profile of the horizontal wind speed used at the inflow boundary of the LES model (RIAM-COMPACT). The profile is based on the WRF-ARW mesoscale meteorological model simulation.

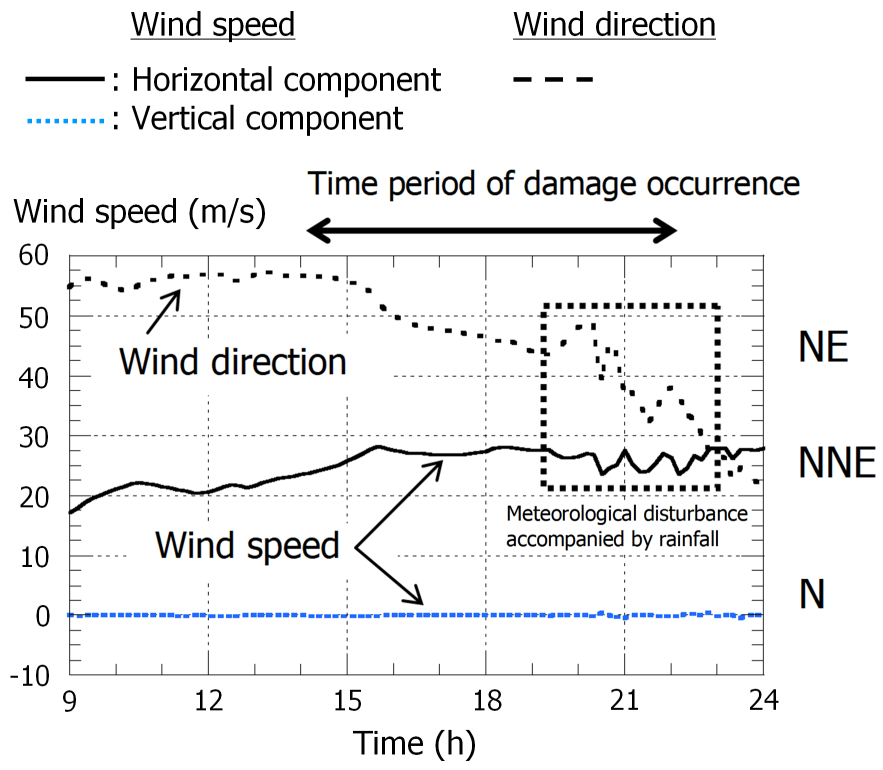

Figure 11. Temporal change of wind speed and direction at a height of $681 \mathrm{~m}$ above the ground surface at the inflow boundary of the LES model (RIAM-COMPACT) on 7 October 2009. Results from Domain 3 of the WRF-ARW mesoscale meteorological model.

domain of the LES model (RIAM-COMPACT) and is treated as the reference spatial scale. Figure 11 also shows that the wind direction aloft changed from north-easterly to northerly between 14:00 pm and 22:00 pm on 7 October, the time period in which the incidences of wind turbine blade damage occurred. In this time period, the average wind speed ranged between approximately 25 and $27 \mathrm{~m} / \mathrm{s}$. The magnitudes of fluctuations of both the wind speed and direction became large starting at 19:00 pm. As discussed earlier, these fluctuations coincided with the passage of a meteorological disturbance accompanied by rainfall. 
Subsequently, simulation results on the temporal change of the airflow characteristics during the time of the incidences of wind turbine blade damage will be discussed. In these simulations, the wind direction was set to a number of wind directions observed from the time of the incidences, which varied between northerly and north-easterly.

Figure 12 shows an example of the simulation results from the LES model (RIAM-COMPACT). These results are from north-easterly wind conditions and show the streamwise wind velocity $(\mathrm{x})$ component along vertical cross-sections which include the Wind Turbine \#20. Air masses with large wind velocity fluctuations were generated by the topography upwind of the wind farm, moved in the streamwise ( $\mathrm{x}$ ) direction, and flowed into the wind farm intermittently. As a result, large wind velocity fluctuations occurred in the wind farm area. The formation site of the air masses with large wind velocity fluctuations and the direction of movement of such air masses vary according to the wind direction. Thus, the temporal change of the wind speed at the nacelle height of each wind turbine generator varies depending on the wind direction.

A close examination of the observational data from the cup and vane anemometer deployed on one of the wind turbine nacelle (\#17) reveals that large temporal changes of the wind speed and direction occurred in the time period in which both tower vibrations and wind turbine blade damage occurred (Figure 13(a)). In this time period, the turbulence intensity also reached approximately $50 \%$ of the average wind speed (Figure 13(a)). The simulation results from the LES model (RIAM-COMPACT) from the same time period (Figure 13(b)) show that the simulated value of the turbulence intensity is smaller than the observed value (Figure 13(a)). This result is attributable to the high-frequency wind velocity fluctuations which could not be simulated by the model. Nonetheless, the simulated values of the turbulence intensity exceeded $30 \%$, and it is evident that the behavior of the temporal change of the simulated wind speed and direction is similar to that of the observed wind speed and direction.

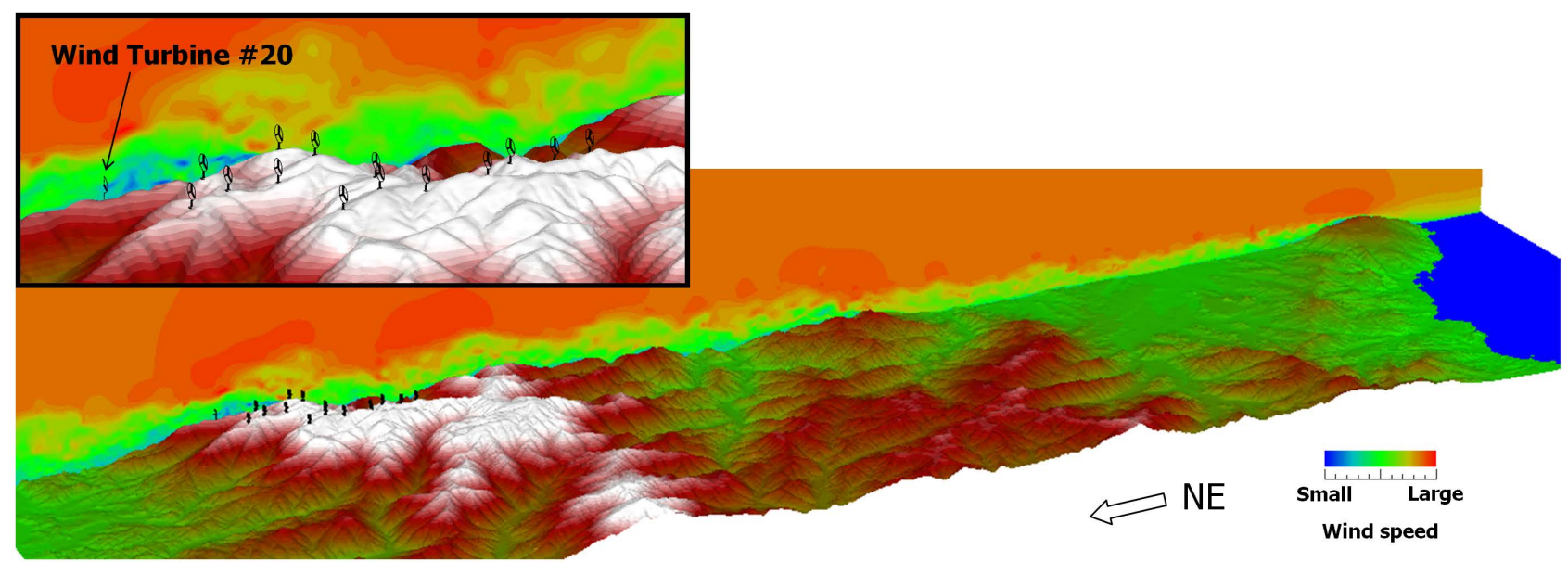

Figure 12. An example of the LES (RIAM-COMPACT) simulation results. North-easterly wind conditions. Shading map for the streamwise (x) wind velocity component along vertical cross-sections which include the Wind Turbine \#20. 

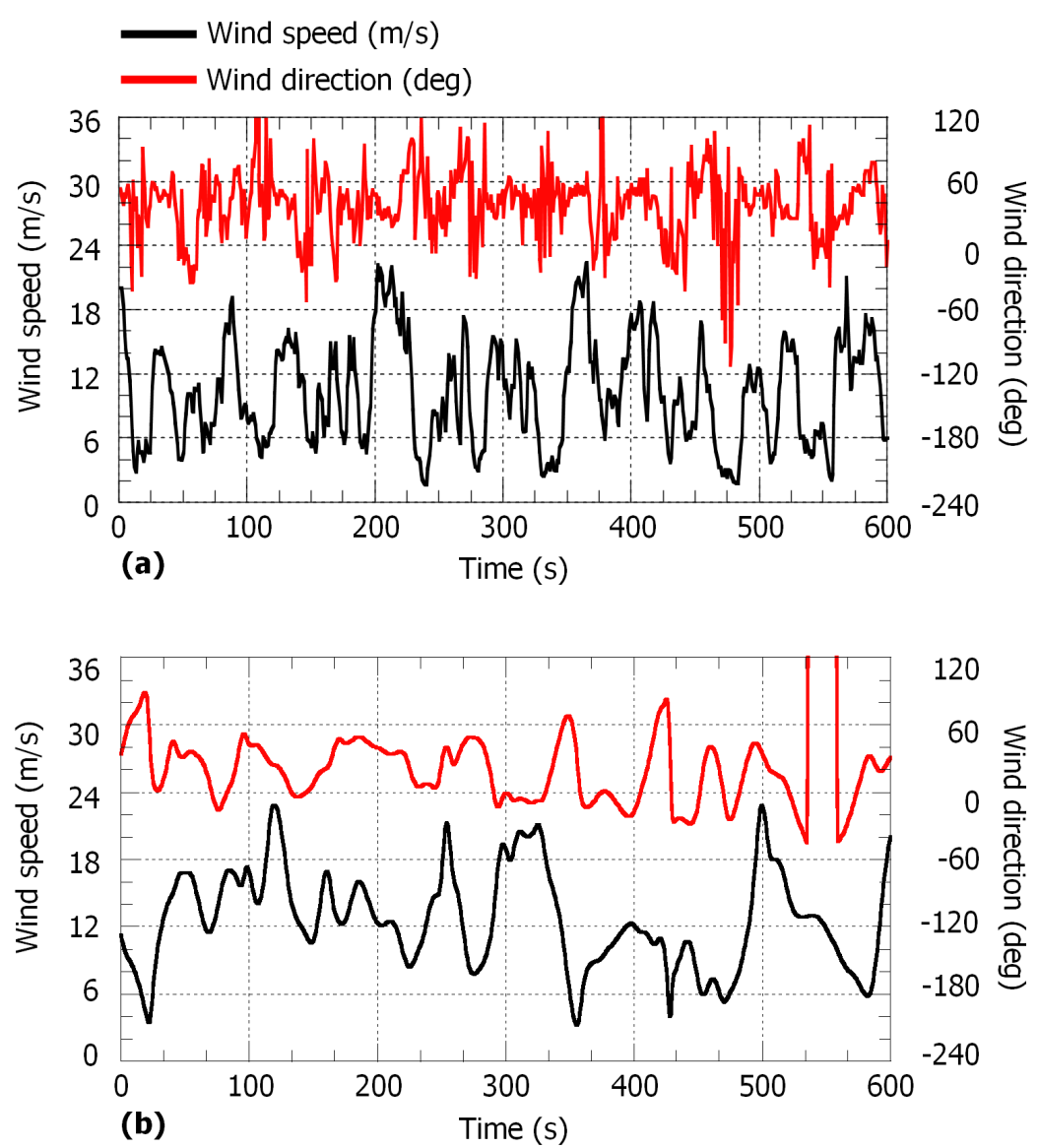

Figure 13. An example 10-minute time-series of wind speed and direction at the wind turbine hub-height (approx. $85 \mathrm{~m}$ above the ground surface), Wind Turbine \#17. (a) Observed values, average wind speed: $8.4 \mathrm{~m} / \mathrm{s}$, turbulence intensity: $54 \%$; (b) LES simulation values, average wind speed: $12.6 \mathrm{~m} / \mathrm{s}$, turbulence intensity: $35 \%$.

Generally, when the average wind speed at a wind power generation site is small, the pitch angles of the blades are controlled so that large amounts of wind power can be generated in order to increase power generation efficiency. When the rate of airflow change is higher than that of the pitch angle control, a wind load large enough to cause blade damage can be exerted on the blades. Airflow change of this nature is one of the major causes of blade damage. The temporal change in the airflow shown in Figure 13 is an example of the sudden changes in airflow under discussion. In such wind conditions, the values of both the turbulence intensity and the gust factor of the airflow are significantly large.

To summarize, the LES model (RIAM-COMPACT) simulation results of the airflow characteristics for the wind farm area suggest that the model was, in a qualitatively accurate manner, able to simulate the rapid fluctuations in wind speed and direction observed at the wind turbine generators. These fluctuations in wind speed and direction occurred as a result of the influence of the topography upwind of the wind turbine generators. The values of the turbulence intensity evaluated from the LES model were approximately $10 \%$ to $20 \%$ smaller than the observed values. 


\section{Analysis of Airflow around Wind Turbine Blades with a RANS Turbulence Model and Stress Analysis with a Finite Element Method (FEM)}

As discussed in Section 3, in the time period for which the wind synopsis simulation was performed, the wind turbine generators were operated in the presence of significant fluctuations of wind speed and direction and were controlled in such a way that they would be able to generate the rated output.

For these conditions, it is speculated that the pitch angle and yaw angle controls were sometimes not able to respond appropriately to the wind speed and direction changes, respectively. Accordingly, the conditions logged in the wind turbine operation record from the time of the blade damage incidences are sorted according to the wind speed, wind direction deviation, blade rotational speed, and pitch angle. For each of the sorted conditions, a fluid analysis (RANS analysis) is performed for the airflow around the turbine blades, and the wind pressure exerted on the blades is evaluated. The conditions which lead to blade damage are investigated using a conventional Finite Element Method (FEM) analysis (refer to Figures 14-16, and Table 1).

The analysis results reveal that large values of stress occurred at the junction between the dorsal and ventral sides of the leading edge (LE) (the LE dorsal-ventral junction, hereafter) and that the locations at which these values occurred matched the locations of the actual damage. Furthermore, enhanced values of stress were confirmed for Analysis Conditions 1 and 2 compared to

Table 1. Conditions for RANS and FEM analyses.

\begin{tabular}{|c|c|c|c|c|c|}
\hline Analysis & $\begin{array}{l}\text { Wind speed } \\
\qquad(\mathrm{m} / \mathrm{s})\end{array}$ & $\begin{array}{l}\text { Wind direction } \\
\text { deviation (deg) }\end{array}$ & $\begin{array}{c}\text { Rotational } \\
\text { speed (rpm) }\end{array}$ & $\begin{array}{l}\text { Blade pitch } \\
\text { angle (deg) }\end{array}$ & Simulated condition \\
\hline 1 & 30 & 0 & 16.5 & 0 & $\begin{array}{l}\text { High wind-pitch angle } \\
\text { control cannot } \\
\text { respond appropriately } \\
\text { to changing wind } \\
\text { conditions }\end{array}$ \\
\hline 2 & 30 & -40 & 16.5 & 0 & $\begin{array}{l}\text { High wind-pitch and } \\
\text { yaw control cannot } \\
\text { respond appropriately } \\
\text { to changing wind } \\
\text { conditions }\end{array}$ \\
\hline
\end{tabular}

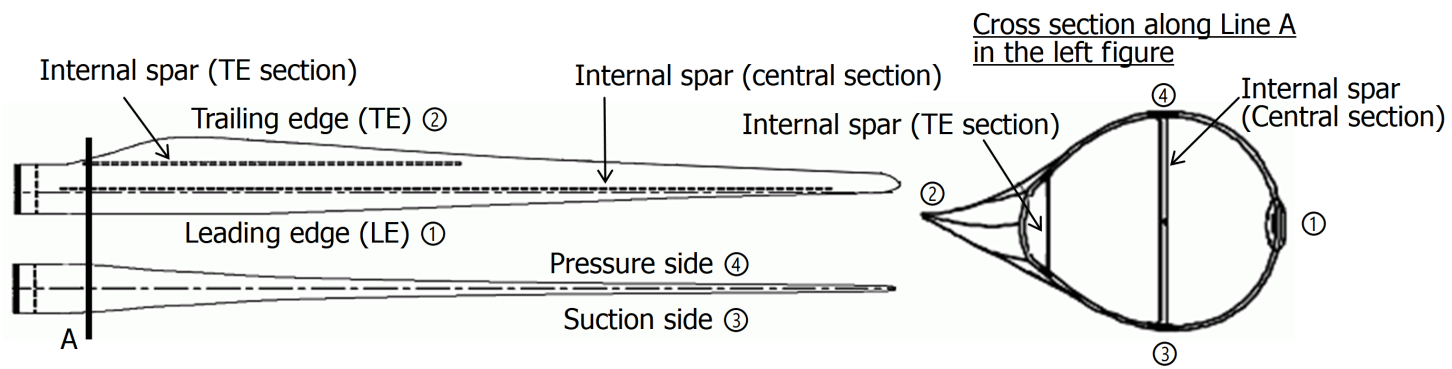

Figure 14. Overall view (left) and cross section (right) of a wind turbine blade. 


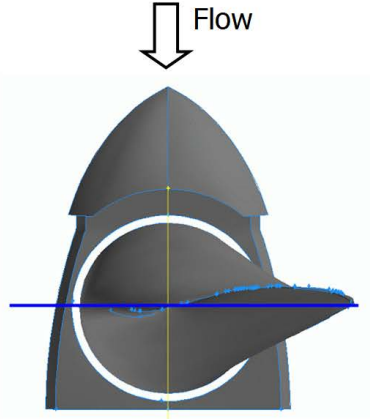

(a) Pitch angle : 0 degs

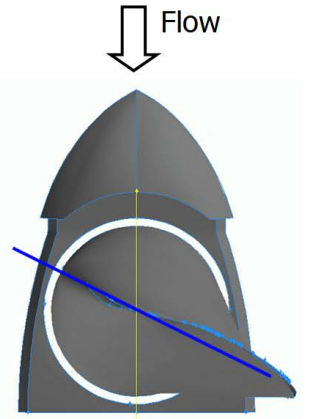

(b) Pitch angle : 30 degs

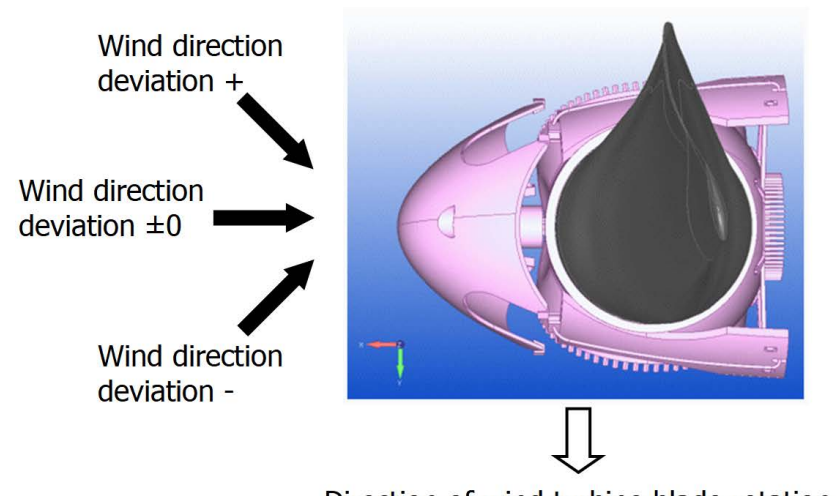

Direction of wind turbine blade rotation

Figure 15. Definitions of blade pitch angle (top) and wind direction deviation (bottom).
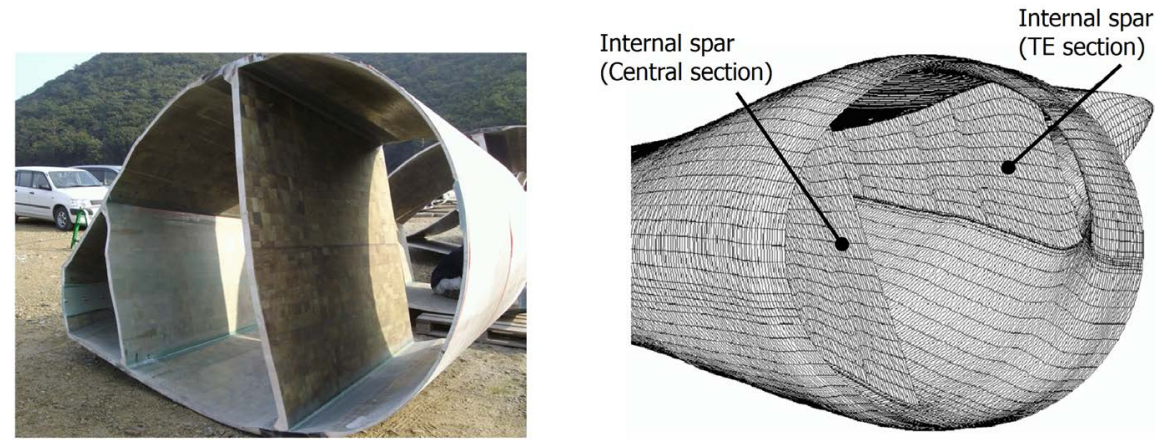

Figure 16. Photo of blade structure (left) and FEM analysis model (right).

normal operating conditions. Analysis Condition 1 represents the condition that the pitch control is unable to appropriately respond to the changing wind conditions while the pitch angle of the blades is set to 0 degrees and wind gusts of 30 $\mathrm{m} / \mathrm{s}$ strike the wind turbine blades. In Analysis Condition 2, a wind direction deviation is included as an additional condition (refer to Figure 17). In both conditions, the values of stress increased compared to those from the time of normal operation with low wind fluctuations.

Although the tensile strength of the adhesive material used for the LE dorsal-ventral junction is quite high, the adhesive material will likely break when repeated loading is applied to the junction, which causes low-cycle fatigue on the 


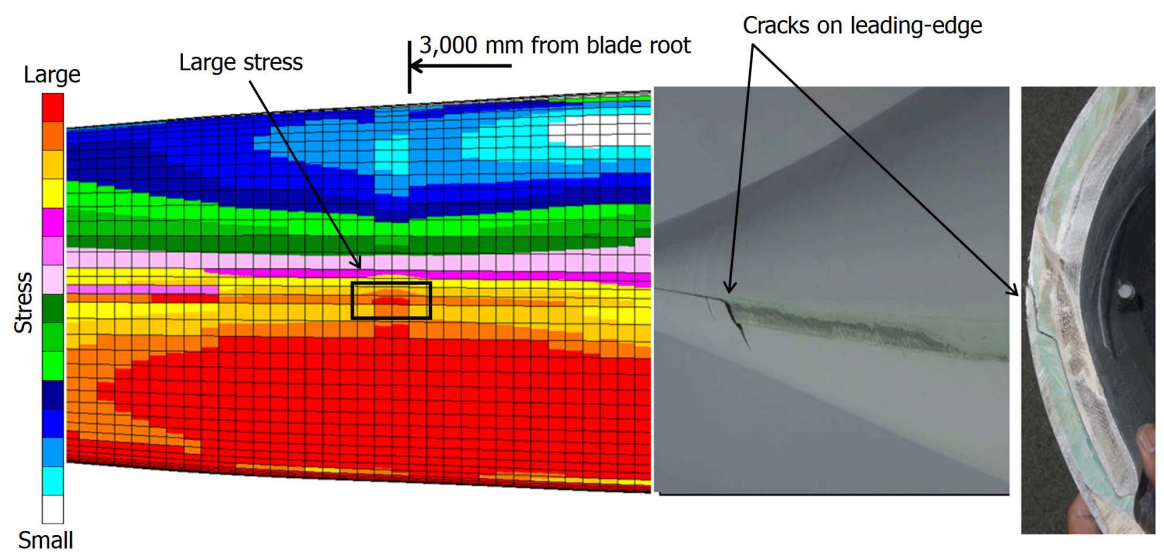

Figure 17. Distribution of stress in the blade-axis direction (Analysis Condition 2 in Table 2) and photos of actual damage.

LE dorsal-ventral junction. During the passage of Typhoon 0918, a large number of wind direction deviations were observed under high wind conditions. Therefore, it can be speculated that cracks formed at the LE dorsal-ventral junction as a result of low-cycle fatigue and the cracks propagated further during subsequent wind turbine operation.

Based on the finding that cracks form in the adhesive material as a result of large values of stress exerted at the LE dorsal-ventral junction, a few measures are explored to prevent future occurrences of similar incidences. Specifically, in order to address low-cycle fatigue, 1) the LE dorsal-ventral junction is over-laminated (Figure 18); 2) more internal reinforcing ribs are added in the LE section; and 3) the internal spars are strengthened. In order to examine the effects of these modifications, another FEM investigation is performed for the reinforced simulated blades for Analysis Condition 2 from Table 1. Figure 19 shows one result of this analysis, suggesting that the values of stress in the LE section were reduced to $30 \%$ of the original values and no cracks would form under meteorological conditions equivalent to those that were present with Typhoon 0918.

\section{Conclusions}

Typhoon \#18 from 2009 moved north-eastward to the south of Japan's main island, Honshu. As a result, the Shiratakiyama Wind Farm area was located far away from the center of the typhoon, and also to the west of the typhoon track. When the wind farm is to the west of the typhoon track, the influence of typhoons on the wind farm area is generally thought to be small. However, due to the influence of the high pressure in the region to the north of the typhoon, a large pressure gradient was present in that region, and easterly high winds which were present in that region flowed into the wind farm.

The most frequently occurring wind direction in the Shiratakiyama area is northerly. It is rare that winds with high speed flow into the wind farm from the east or northeast as in the case investigated in the present study. The results 


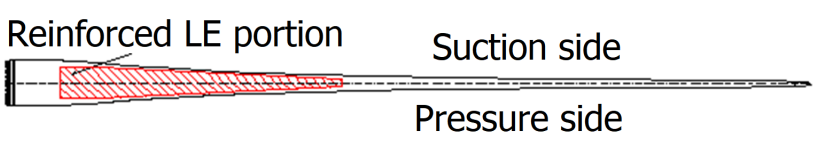

Figure 18. Reinforced (over-laminated) LE dorsal-ventral junction.

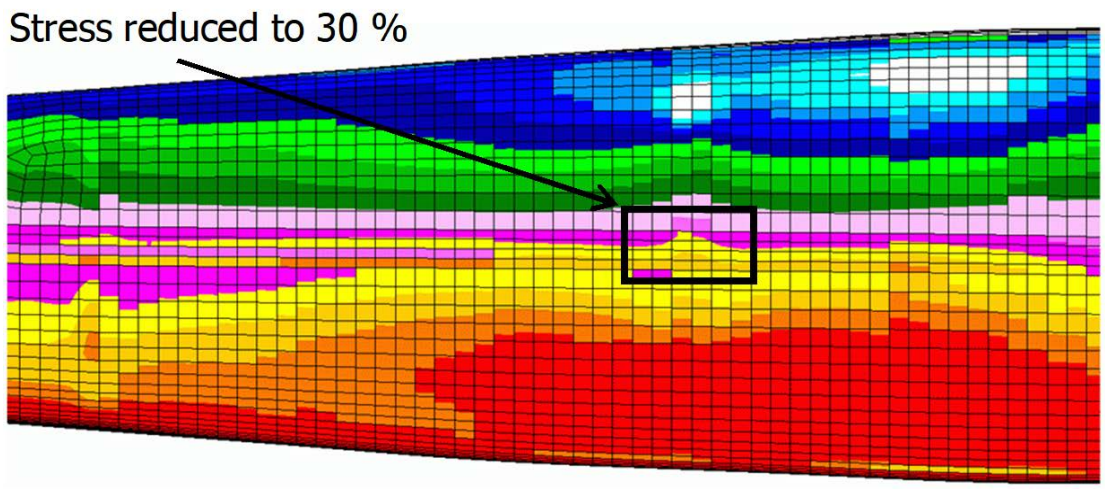

Figure 19. Distribution of stress in the blade axis direction after reinforcing the wind turbine blade (Analysis Condition 2 in Table 1).

from the LES model (RIAM-COMPACT) simulation revealed that in time periods with high winds flowing from the north-east, winds with rapid fluctuations in wind speed and direction encountered the wind turbines. The rapid fluctuations in wind speed and direction originated from the topography upwind of the wind farm.

In meteorological conditions similar to those under consideration, the pitch angle control cannot appropriately respond to the wind velocity fluctuations, and the value of the wind pressure on the turbine blades may exceed that presumed at the time of designing. The FEM analysis results also suggested that the junction between the dorsal and ventral sides of the LE was subject to large values of stress when the pitch control was unable to respond appropriately to the wind velocity fluctuations. The locations at which large values of stress were predicted by the model simulation matched those of the actual damage.

The warning record of the wind turbines shows that wind direction deviation was observed quite frequently in high winds, which leads to the following speculation. With the stress which occurred from such meteorological conditions and repeatedly affected the LE dorsal-ventral junction, low-cycle fatigue caused the formation of cracks along this junction, and the cracks propagated further with subsequent operation of the wind turbines.

A few measures were explored to prevent future occurrences of wind turbine blade damage: 1) over-lamination of the LE dorsal-ventral junction; 2) addition of more internal reinforcing ribs; and 3) reinforcement of internal spars. These modifications were made in order to address low-cycle fatigue on the LE dorsal-ventral junction. In the FEM analysis in which the simulated wind turbine blades were reinforced with the above modifications, the values of stress exerted on the LE section. 
Finally, by closely examining the series of analysis results from the present study in a comprehensive manner, we are in the process of identifying guidelines for safely regulating wind turbine operations which will allow adequate power generation without exerting large wind loading on the wind turbine blades. In other words, guidelines which would maintain a high value of the availability factor for a wind power facility are being sought. The finalized guidelines are intended to be used for regulating actual wind turbine operations in the future.

\section{Acknowledgements}

This work was supported by JSPS KAKENHI Grant Number 17H02053. Also, a part of the present study was supported by Dr. Takashi Maruyama (Kyoto University) and Dr. Hirohiko Ishikawa (Kyoto University). Observed data was provided by Kinden Corporation. The author expresses appreciation to them.

\section{References}

[1] Skamarock, W.C., et al. (2008) A Description of the Advanced Research WRF Version 3. http://www2.mmm.ucar.edu/wrf/users/docs/arw_v3.pdf

[2] Uchida, T. and Ohya, Y. (2008) Verification of the Prediction Accuracy of Annual Energy Output at Noma Wind Park by the Non-Stationary and Non-Linear Wind Synopsis Simulator, RIAM-COMPACT. Journal of Fluid Science and Technology, 3, 344-358. https://doi.org/10.1299/jfst.3.344

[3] Uchida, T. and Ohya, Y. (2008) Micro-Siting Technique for Wind Turbine Generators by Using Large-Eddy Simulation. Journal of Wind Engineering \& Industrial Aerodynamics, 96, 2121-2138. https://doi.org/10.1016/j.jweia.2008.02.047

[4] Uchida, T., Maruyama, T. and Ohya, Y. (2011) New Evaluation Technique for WTG Design Wind Speed Using a CFD-Model-Based Unsteady Flow Simulation with Wind Direction Changes. Modelling and Simulation in Engineering, 2011, Article ID: 941870. http://dx.doi.org/10.1155/2011/941870

[5] Uchida, T., Ohya, Y. and Sugitani, K. (2011) Comparisons between the Wake of a Wind Turbine Generator Operated at Optimal Tip Speed Ratio and the Wake of a Stationary Disk. Modelling and Simulation in Engineering, 2011, Article ID: 749421. http://dx.doi.org/10.1155/2011/749421

[6] Uchida, T. and Ohya, Y. (2011) Latest Developments in Numerical Wind Synopsis Prediction Using the RIAM-COMPACT CFD Model. Energies, 4, 458-474. https://doi.org/10.3390/en4030458

[7] Uchida, T. (2017) High-Resolution LES of Terrain-Induced Turbulence around Wind Turbine Generators by Using Turbulent Inflow Boundary Conditions. Open Journal of Fluid Dynamics, 7, 511-524. https://doi.org/10.4236/ojfd.2017.74035

[8] Uchida, T. (2017) Large-Eddy Simulation and Wind Tunnel Experiment of Airflow over Bolund Hill. Open Journal of Fluid Dynamics, 8, 30-43. https://doi.org/10.4236/ojfd.2018.81003

[9] Uchida, T. (2017) High-Resolution Micro-Siting Technique for Large Scale Wind Farm Outside of Japan Using LES Turbulence Model. Energy and Power Engineering, 9, 802-813. https://doi.org/10.4236/epe.2017.912050

[10] Uchida, T. (2017) CFD Prediction of the Airflow at a Large-Scale Wind Farm above a Steep, Three-Dimensional Escarpment. Energy and Power Engineering, 9, 829-842. https://doi.org/10.4236/epe.2017.913052 
[11] Smagorinsky, J. (1963) General Circulation Experiments with the Primitive Equations, Part 1, Basic Experiments. Monthly Weather Review, 91, 99-164. https://doi.org/10.1175/1520-0493(1963)091<0099:GCEWTP>2.3.CO;2

[12] Sumner, J., Watters, C.S. and Masson, C. (2010) Review: CFD in Wind Energy: The Virtual, Multiscale Wind Tunnel. Energies, 3, 989-1013.

https://doi.org/10.3390/en3050989 